\title{
我国电子陶瓷技术发展的战略思考
}

\author{
周济, 李龙士, 熊小雨 \\ （清华大学材料学院, 北京 100084)
}

摘要: 电子陶瓷作为一类重要的战略新材料, 是无源电子元件的核心材料, 也是电子信息技术领域重要的技术前沿。随着电 子信息技术日益走向集成化、智能化和微型化, 无源电子元件日益成为电子元器件技术的发展瓶颈, 电子陶瓷材料及其制备 加工技术的战略地位日益凸显。我国电子陶瓷材料和元件领域已形成了很好的产业技术基础, 但在高端材料和元器件方面的 竞争力依然不足, 一些关键材料技术、工艺技术及设备技术受制于人。研究认为: 面对新形势, 亟待加大研发投入, 理顺体 制机制, 强化产业链的自主可控和自主创新。

关键词：电子陶瓷；无源电子元件；高端材料

中图分类号: TQ174 文献标识码: A

\section{Strategic Thinking on the Development of Electronic Ceramic Technology in China}

\section{Zhou Ji, Li Longtu, Xiong Xiaoyu}

(School of Materials Science and Engineering, Tsinghua University, Beijing 100084, China)

\begin{abstract}
Electronic ceramics are a type of new materials of strategic significance. They are the core materials of passive electronic components and an important technology frontier in the electronic information technology field. As the electronic information technology develops toward integration, intelligence, and miniaturization, passive electronic components have become a bottleneck restraining the development of electronic component technology. Therefore, the strategic position of electronic ceramic materials and their processing technologies is increasingly prominent. The field of electronic ceramic materials and components has formed a good industrial technology foundation in China. However, its competitiveness is still insufficient in high-end materials and components, and some key material, process, and equipment technologies are controlled by other countries. Facing the new situation, it is urgent to increase R \& D investment, rationalize the system and mechanism, and strengthen the independence and innovation of the industrial chain.
\end{abstract}

Keywords: electronic ceramics; passive electronic components; high-end materials

\section{一、前言}

电子陶瓷是无源电子元件的核心材料, 是电子 信息技术的重要材料基础。近年来, 随着电子信息
技术日益走向集成化、薄型化、智能化和微型化, 以半导体技术为基础的有源器件和集成电路迅速发 展, 而无源电子元件日益成为电子元器件技术的发 展瓶颈, 因此电子陶瓷材料及其制备加工技术越来

收稿日期 : 2020-07-12; 修回日期 : 2020-08-27

通讯作者: 周济, 清华大学材料学院教授, 中国工程院院士, 主要研究方向为材料科学与工程; E-mail: zhouji@tsinghua.edu.cn 资助项目：中国工程院咨询项目“新材料强国 2035 战略研究” (2018-ZD-03)

本刊网址：www.engineering.org.cn/ch/journal/sscae 
越成为制约电子信息技术发展的重要核心技术之 一 [1 3]。

我国是无源电子元件大国, 从产品产量上看, 无源元件的产量占到了全球的 $40 \%$ 以上; 但不是 强国，元件产值不足全球产值的四分之一，高端元 件大量依赖进口 $[4,5]$ 。电子陶瓷材料及技术是制约 高端元件发展的重要因素之一。从战略高度研判国 内外电子陶瓷材料与元器件技术的发展现状, 分析 我国相关领域的问题及对策, 对于推动我国高端电 子元器件产业的发展具有重要意义。

\section{二、国际电子陶瓷产业技术发展现状与趋势}

从全球电子陶瓷产业技术水平看，日本和美国 处于世界的领先地位。其中，日本凭借其超大规模 的生产和先进制备技术，在世界电子陶瓷市场中具 有主导地位，占有世界电子陶瓷市场 50\% 以上的 份额 [2]。美国在基础研究和新材料开发方面力量 雄厚, 其注重产品的前沿技术和在军事领域的应用, 如在水声、电光、光电子、红外技术和半导体封装 等方面处于优势地位。此外, 韩国在电子陶瓷领域 发展迅速, 引人瞩目。

\section{（一）多层陶瓷电容器（MLCC）产业}

电子陶瓷的主要应用领域是无源电子元件。 MLCC 是目前用量最大的无源元件之一，主要用于 各类电子整机中的振荡、耦合、滤波旁路电路中， 其应用领域涉及自动仪表、数字家电、汽车电器、 通信、计算机等行业。MLCC 在国际电子制造业中 占据越来越重要的位置, 尤其是随着消费类电子产 品、通信、电脑、网络、汽车、工业和国防终端客 户的需求日益增多，全球市场达到百亿美元，并以 每年 10\% 15\% 的速度增长。自 2017 年以来, 由于 供求关系所致, MLCC 产品发生了若干次涨价潮。 日本是 MLCC 的生产大国, 日本的村田（nuRata）、 京瓷株式会社 (KYOCERA)、太阳诱电株式会社 (TAIYO YUDEN)、TDK-EPC, 韩国的三星电机有 限公司（SEMCO）和我国台湾地区的华新科技股 份有限公司、国巨股份有限公司等都是全球著名的 MLCC 生产企业。MLCC 的主流发展趋势是小型化、 大容量、薄层化、贱金属化、高可靠性，其中内电 极贱金属化相关技术在近年来发展最为迅速，采
用贱金属内电极是降低 MLCC 成本的最有效途径, 而实现贱金属化的关键技术是发展高性能抗还原钛 酸钡瓷料。日本在 21 世纪初就已经完成了此项技 术的开发，并一直保持世界领先，目前其大容量 MLCC 全部实现了贱金属化。尺寸的小型化一直是 MLCC 发展的主要趋势，随着电子设备日益向小型 化和便携式方向发展, 产品更新换代迅速, 小型化 产品需求强烈, 如图 1 所示。实现小型化元器件的 基本材料技术是陶瓷介质层的薄型化技术。当前日 本企业处于国际领先地位, 其生产的 MLCC 单层 厚度已达 $1 \mu \mathrm{m}$, 其中，处于顶级地位的日本村田 和太阳诱电株式会社的研发水平已达到 $0.3 \mu \mathrm{m}$ 。介 质薄层化的基础是介质材料的微细化。在大容量薄 层化 MLCC 元件单层厚度逐渐减小的同时, 为保 证元件的可靠性，钛酸钡作为 MLCC 陶瓷介质的 主晶相, 其颗粒尺寸需要从 200 300 nm 进一步细 化到 80 150 nm。未来的发展趋势是制备出颗粒尺 寸 $\leqslant 150 \mathrm{~nm}$ 的钛酸钡材料作为 MLCC 介质层的主 晶相材料。

\section{（二）片式电感器产业}

片式电感器是另一类用量较大的无源电子元 件, 是三大类无源片式元件中技术最复杂的一类, 其核心材料是磁性陶瓷 (铁氧体)。目前世界片式 电感器的总需求量在 10000 亿只左右, 年增长速度 在 $10 \%$ 以上。在研制生产片式电感器方面, 日本 的生产产量约占世界总量的 $70 \%$ 。其中 TDK-EPC、 村田和太阳诱电株式会社一直掌握该领域的前沿技 术。据产业情报网 (IEK) 统计, 在全球电感市场中, TDK-EPC、太阳诱电株式会社及村田三家企业的产

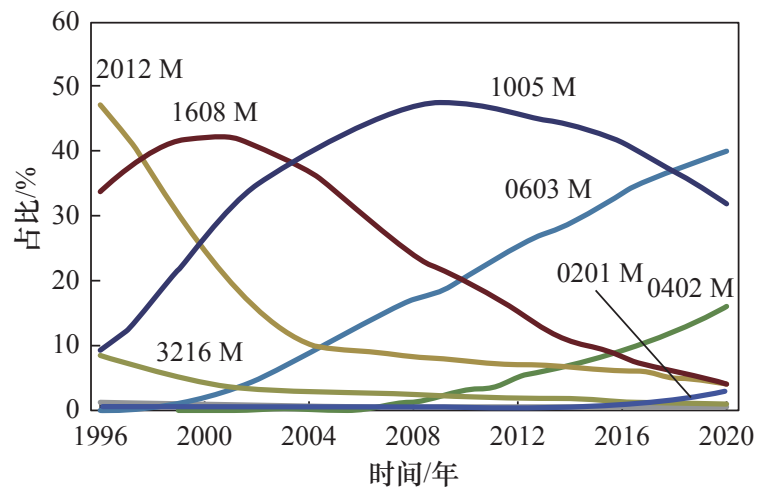

图 1 近年来各种尺寸 MLCC 的市场占比变化 [6] 
量合计约占全球市场的 $60 \%$ 左右。片式电感器发 展的主要趋势包括小尺寸、高感量、大功率、高频 率以及高稳定、高精度。其技术核心是具有低温烧 结特性的软磁铁氧体和介质材料。

\section{（三）高性能压电陶瓷产业}

压电陶瓷是一种重要的换能材料, 其机电耦合 性能优良, 在电子信息、机电换能、自动控制、微 机电系统、生物医学仪器中广泛应用。为适应新的 应用需求, 压电器件正向多层化、片式化和微型化 方向发展。近年来, 多层压电变压器、多层压电驱 动器、片式化压电频率器件等一些新型压电器件不 断被研制, 并广泛应用于电气、机电、电子等领域。 同时, 在新型材料方面, 无铅压电陶瓷的研制已取 得了较大的突破, 有可能使得无铅压电陶瓷在许多 领域替代锆钛酸铅 (PZT) 基的压电陶瓷, 推动绿 色电子产品的升级换代。此外, 压电材料在下一代 能源技术中的应用开始崭露头角。过去十年中, 随 着无线与低功耗电子器件的发展, 利用压电陶瓷的 微型能量收集技术的研究与开发受到各国政府、机 构和企业的高度重视。

\section{（四）微波介质陶瓷产业}

微波介质陶瓷是无线通信器件的基石。广泛 应用于移动通信、导航、全球卫星定位系统、卫 星通信、雷达、遥测、蓝牙技术以及无线局域 网（WLAN）等领域 [7]。由微波介质陶瓷构成的 滤波器、谐振器及振荡器等元器件在 $5 \mathrm{G}$ 网络中被 广泛使用, 其质量在很大程度上决定了微波通信产 品的最终性能、尺寸极限与成本。具有低损耗、高 稳定性、可调制的微波电磁介质材料是目前国际上 的核心技术。微波介质陶瓷材料在发展初期曾形成 美国、日本、欧洲等国家和地区激烈竞争的局面， 但随后日本逐渐处于明显的优势地位。随着第三 代移动通信与数据微波通信的快速发展, 美国、

本、欧洲均针对该高技术领域的发展进行战略上的 调整。从最近的发展趋势看, 美国将非线性微波介 质陶瓷与高介电常数微波介质陶瓷材料技术作为战 略重点, 欧洲侧重于固定频率谐振器用材料, 而日 本则依靠其产业化的优势大力推进微波介质陶瓷的 标准化与高品质化 [7]。目前微波介质材料和器件
的生产水平以日本村田、京瓷株式会社、TDK-EPC 公司, 美国 Trans-Tech 公司等为最高。

\section{（五）半导体陶瓷产业}

半导体陶瓷是一类可以将湿、气、力、热、 声、光、电等物理量转化为电信号的信息功能陶瓷 材料, 应用十分广泛, 是物联网技术的主要基础 材料, 如正温度系数热敏电阻 (PTC)、负温度系 数热敏电阻 (NTC) 和压敏电阻, 以及气敏、湿 敏传感器等。热敏陶瓷和压敏陶瓷的产量和产值在 半导体陶瓷材料中最高。在国际上, 热敏电阻陶瓷 材料及器件以日本村田、芝浦电子株式会社、三菱 集团（Mitsubishi）、TDK-EPC、石冢电子株式会 社 (Ishizuka), 美国威世 (VISHAY), 德国爱普科 斯 (EPCOS) 等公司的技术最先进, 产量最大, 他 们的年产量总和约占世界总量的 $60 \%$ $80 \%$, 其产 品质量好的同时价格也高。近年来, 国外陶瓷半导 体器件正向高性能、高可靠、高精度、多层片式化 和规模化方向发展。目前, 国外一些大企业相继推 出了一些基于多层陶瓷技术的片式化半导体陶瓷器 件, 成为敏感器件领域的高端产品。

\section{三、我国电子陶瓷材料与元器件的发展现状}

我国是电子元件大国, 多种电子陶瓷产品的产 量居世界首位, 已经形成了一批在国际上拥有一定 竞争力的元器件产品生产基地, 同时拥有全球最大 的应用市场。然而, 目前高端电子陶瓷材料市场主 要为日本企业所垄断, 国内生产的材料少部分用于 高端元器件产品, 大部分用于中低端元器件产品; 国内高水平科研成果在转化过程中遭遇来自原材 料、生产装备、稳定性等方面的瓶颈, 所占市场份 额相对较低。

在产业技术方面, 我国的电子陶瓷及其元器件 产品生产基地已经形成了相当的规模, 并拥有国际 先进的生产水平。其中风华高新科技股份有限公司 是国际上为数不多的集电子元器件、电子材料、电 子专用设备 “三位一体” 的产业体系的综合性企业; 顺络电子股份有限公司在片式电感器和低温共烧陶 瓷（LTCC）产品方面在国际上竞争优势明显; 潮 州三环 (集团) 股份有限公司、深圳宇阳科技发展 
有限公司等陶瓷电子元器件行业中的龙头骨干企业 也都在国际上具有一定影响力, 得到了国家一系列 研发计划的支持。由清华大学和风华高新科技股份 有限公司牵头, 联合 20 家大中型企业、研究机构 和高校组建的电子技术创新战略联盟对于推动功能 陶瓷片式元器件与无源集成产业陶瓷材料研究开发 和产业的结合发挥了重要作用。

\section{（一）MLCC 产业}

我国 MLCC 行业规模较大, 已经形成了一批 以风华高新科技股份有限公司、深圳宇阳科技发展 有限公司为代表的具有国际竞争力的大企业, 并在 国际竞争中占有一席之地。然而, 由于全球顶级的 MLCC 制造厂商如日本的太阳诱电株式会社、村 田、京瓷株式会社、TDK-EPC 和韩国的三星电机 有限公司等大型企业陆续在中国内地建立了制造基 地, 把产能向中国大陆转移, 目前国内一半以上的 MLCC 产量被外资和合资企业占据。同时，国内市 场高端 MLCC 产品主要依赖进口。由于缺少自主 知识产权和先进工艺设备, 高性能陶瓷粉体、电极 浆料、先进生产设备都大量依赖于国外厂商。从市 场情况看, MLCC 消费主要集中在亚洲, 占全球 MLCC 消费量的 $75 \%$, 而中国占到一半以上。随 着移动通信产品等整机制造业的不断扩张, 我国的 MLCC 产品需求仍在迅速增长。

\section{（二）片式电感器产业}

我国从 20 世纪 90 年代初开始开发、生产片式 电感器及相关材料。目前已基本建立起了一个传统 与新型产品兼顾、具有相当经济规模、在国际市场 占据一定地位的电感器行业, 产量约占世界总产量 的 20\%。其中深圳顺络电子股份有限公司已经凭借 材料和工艺方面的技术优势在国际竞争中占有一席 之地。然而, 目前国内片式电感生产厂商依然存在 一些问题，大部分产品面向消费类电子产品，应用 于通信领域和汽车电子领域的这类基础元件主要被 日本、韩国和我国台湾的企业所垄断。同时, 低端 市场的价格战造成了国内片式电感生产厂商利润空 间的萎缩。目前, 全球市场对片式电感器的需求在 不断增长, 市场结构也在不断变化, 尤其是移动 / 无线通信领域的增长速度惊人。以手机为代表的移
动通信产品的生产厂家大部分在中国, 而目前大部 分用于移动通信的片式电感器件由国外供货。计算 机和汽车电子也是国内对高端片式电感器产品需求 增长较快的领域。未来一段时期, 我国在高端片式 电感器方面的市场缺口会相当大。

\section{（三）高性能压电陶瓷产业}

在高性能压电陶瓷及元器件方面, 我国内地压 电陶瓷企业数量较多, 但多数企业是中小企业, 产 品结构以低端产品为主。尽管在过去几十年中我国 压电陶瓷的研究开发取得了一批有自主知识产权 的技术成果。但从目前行业的总体情况看, 其市 场竞争力、产业技术水平函待提高, 产品结构有 待升级。随着信息技术、新能源技术、生物医学 以及航空航天技术的迅速发展，一些新型的压电 陶瓷器件的应用市场将迅速崛起, 成为压电陶瓷 器件的市场主体。

\section{（四）微波介质陶瓷产业}

在微波介质陶瓷材料方面, 我国微波电磁介质 的研究起步较早，基本上与发达国家同步，早期主 要围绕国防军工上的关键微波器件的需求开展研究 开发和生产。近十几年来, 形成了若干个一定规模 的企业, 如武汉凡谷电子股份有限公司、佳利电子 有限公司、大富科技股份有限公司、深圳顺络电子 股份有限公司、江苏灿勤科技股份有限公司等。但 这些企业与国际知名大企业相比较, 在技术水平、 产品品种和生产规模上仍有较大差距。以第五代移 动通信 $(5 \mathrm{G})$ 、无线互联网、无线传感网以及以卫 星通信与定位系统为代表的无线信息技术迅速崛 起, 对高性能微波器件提出了更高的要求, 其发展 空间很大。

\section{（五）半导体陶瓷产业}

目前, 国内多数半导体陶瓷及相关敏感器件的 生产企业在 20 世纪 90 年代成立，以外资企业与民 营企业为主体。外资企业以独资或合资的方式在国 内市场迅速建立了生产基地, 其技术优势显著, 产 品性能优良, 出口量较大, 在国内高端市场上占据 着主导地位。从技术方面看, 民营企业生产工艺落 后，在原材料、生产设备、检测设备、质量控制等 
方面还存在较大不足, 导致国内产品线单一, 产品 结构以中低端为主, 无法满足高端市场的需求。从 未来需求方面看, 物联网和传感网的迅猛发展将带 来我国半导体陶瓷传感器需求的爆炸式增长, 未来 还将面临较大的发展空间。

\section{四、电子陶瓷材料重大技术需求分析}

随着电子信息产品进一步向宽带化、小型化、 集成化、无线/移动化、绿色化的方向发展, 电子 陶瓷元器件的多功能化、多层化、多层元件片式化 和片式元件集成化成为发展的主流, 这些新的趋势 向电子陶瓷材料提出了一系列新的要求, 如材料显 微结构细晶化、材料功能的多样化、电磁特性的高 频化及低损耗化等。而相关材料技术日益成为制约 信息技术发展的瓶颈技术。未来若干年, 电子陶瓷 材料的发展亟待解决的关键性技术问题包括以下几 方面。

（1）满足电子元件小型化/微型化的电子信息 系统的新型电子陶瓷材料及其关键技术。如纳米晶 材料制备技术、超薄陶瓷膜成型工艺等; 适用于低 能耗无线 / 移动信息系统中关键微波元器件的超低 损耗介质陶瓷材料等。

（2）适应新一代移动通信技术特征频率的新型 电子陶瓷材料。随着 $5 \mathrm{G} / 6 \mathrm{G}$ 技术的发展, 通信频段 逐渐从微波向毫米波推进, 而适应更高频段的新型 电子陶瓷, 特别是陶瓷介质材料的需求将急剧增加, 发展相关材料和器件迫在眉睫。

（3）用于无源元件集成和无源 - 有源集成与模 块化的新型电子陶瓷材料。以 LTCC 技术为平台的 无源集成技术将有更大的发展空间, 而与该技术相 兼容的各类功能陶瓷材料及其共烧技术是一个亟待 攻克的技术瓶颈。

(4) 面向电子信息系统多功能化的新功能电子 陶瓷材料。具有电、磁、光、热耦合行为和超常电 磁特性的新型多功能陶瓷材料系统, 以及在复杂外 场或极端环境条件下工作具有稳定性和优异服役行 为的新型信息功能陶瓷材料等。

（5）其他技术领域也对电子陶瓷材料提出了新 的需求。在能源材料方面, 固体燃料电池、太阳能 电池和半导体照明技术的进一步发展有赖于电子陶 瓷材料及其制备技术的突破; 随着物联网和传感网
的兴起, 种类繁多、功能各异的传感器要求有更多 和更高性能的新型敏感陶瓷材料的出现。

\section{五、我国电子陶瓷产业发展面临的主要问题}

当前我国在电子陶瓷及其元器件产业发展中面 临的主要问题包括以下几点。

\section{（一）社会重视程度严重不足}

电子陶瓷材料在电子信息技术中的重要地位仅 次于半导体。然而, 与半导体技术相比, 社会各界 的重视程度严重不足。正如日本村田 (中国) 公司 总裁丸山英毅所指出: 中国在国策上对于芯片、半 导体是有扶持的, 但是对于元器件, 没有大的支持 力度, 所以中国的元器件企业更多的是自己发展。 由于社会投入不足, 企业缺乏吸引高水平人才的机 制, 研发力量薄弱, 研发经费缺乏, 难以适应日新 月异的研发需求。

\section{（二）研究成果转化机制有待完善}

国内电子陶瓷材料的研发工作分散于少数高 校、研究院所和少部分大型企业, 在高校和研究院 所中, 分属于材料和元器件的不同领域, 各自的侧 重点差别大, 相互之间脱节, 缺乏材料、工艺、元 器件集成的系统性研究。研发成果向产业化的转化 不及时、不充分。高校、研究院所与企业在体制上 分离, 交流协作不充分, 缺乏一个能将成果及时、 有效转化和具体实现 “产学研” 相结合的有效机制。 高校和研究院所的研究成果往往停留在实验室工作 阶段, 没有产品的小试、量产验证, 而企业中的研 发往往又因实验分析设备的缺乏而不够深入。

\section{（三）国内产业链对自主创新的支撑不完善}

电子陶瓷材料处于产业链中上游, 其前端是 原材料, 后端是元器件。由于元器件工艺设备、 技术标准等主要来自国外, 同时国内原材料产品 在稳定性、一致性方面与国外产品相比尚有差距, 制约了国内电子陶瓷材料在元器件产品中的规模 化应用。特别是一些具有原创性的材料, 由于与 已有元器件技术缺乏兼容性, 难以获得应用, 使 得国内电子陶瓷材料和元器件难以在行业中进入 领跑地位。 


\section{（四）规模化生产工艺装备水平有待提高}

目前国内高端电子陶瓷材料和元器件的工艺装 备仍以进口为主。由于技术更新换代较快, 先进的 技术很难进入国内，导致规模化生产水平难以在全 球处于领导地位。以国内陶瓷无源元件行业的龙头 企业为例，风华高新科技股份有限公司、顺络电子 股份有限公司和宇阳科技发展有限公司均是主要从 事片式元器件生产的国内骨干企业, 但其高端产品 技术水平与国际知名企业 TDK-EPC、太阳诱电株 式会社等都存在很大的差距。

\section{六、电子陶瓷产业发展的战略目标和路径}

\section{（一）总体思路}

进一步加大电子陶瓷材料及相关元器件的研发 投入，重点突破电子陶瓷高端材料、先进加工工艺 技术和装备关键技术, 加速电子陶瓷材料与元器件 全产业链的国产化和自主创新，形成相关技术的自 主知识产权系统和技术优势; 完善电子陶瓷材料 成果产业化的机制，建立具有国际先进水平的电子 陶瓷材料研发系统和生产基地，以及国际一流的元 器件工艺制造基地。使我国在超薄型贱金属内电极 MLCC 及其铁电陶瓷材料产业化技术、低温烧结高 性能片式电感器（MLCI）及其铁氧体材料产业化 技术、高性能压电陶瓷及其新型元器件产业化技术、 高储能密度介电陶瓷材料及其工程化制备技术、微 波介质陶瓷产业化技术以及半导体陶瓷及敏感元器 件产业化技术等若干领域达到国际领先水平。

\section{（二）战略目标}

面向信息技术等领域的迫切需求，进一步加 大电子陶瓷技术的研究开发及其产业升级的扶植 力度，突破困扰该产业技术进步的关键技术，使 我国在该领域的技术水平走进世界前列。力争在 2025 年大部分水平与美国、日本接近，2035 年成 为全球高端电子陶瓷材料和元器件的主要来源地 (见图 2)。

\section{（三）重点发展方向}

\section{1. 新一代电子陶瓷元件与材料}

重点突破量大面广的无源电子元件, 如 MLCC、片式电感器、陶瓷滤波器的器件所需的高
端电子陶瓷材料技术，发展出拥有自主知识产权的 材料配方和规模化生产技术, 形成稳定的生产规模。 重点突破高端电子陶瓷元件中材料精密成型和加工 的关键工艺技术和装备，保证薄型化多层陶瓷技术 所需的关键纳米陶瓷材料的自主稳定供应，形成无 源集成关键设备的自主研发和生产能力。

（1）高性能、低成本 MLCC 材料与元件。加 强高性能抗还原陶瓷介质粉体材料及规模化生产; 重点研发薄型化功能陶瓷成型技术与装备, 纳米 晶陶瓷烧结技术, 超薄型多层陶瓷结构内电极技 术等。

（2）新型片式感性元件与关键材料。加强高 性能低温烧结铁氧体及低介低损耗陶瓷介质粉体 材料及规模化生产; 研发多层陶瓷精密互联技术 及其装备, 小型化微波段片式电感器布线设计技 术等。

（3）高性能多层片式敏感元件与材料。重点研 究高性能片式热敏、气敏、湿敏、压敏、光敏陶瓷 规模化生产技术, 微纳尺度多层片式敏感陶瓷传感 器制备工艺技术与表征技术等。

（4）高性能压电陶瓷材料。重点研究压电陶 瓷材料净尺寸成型与加工及其产业化技术，压电微 型电源应用的高性能多层压电材料制备及产业化技 术，高性能多层无铅压电陶瓷材料和新型元件可工 程化和产业化的先进制备技术。

（5）新一代电磁波介质陶瓷材料。面向 $5 \mathrm{G} / 6 \mathrm{G}$ 通信技术的新型电磁波介质材料, 重点研究片式高 频低损耗微波介质陶瓷及其规模化生产技术，片式 高性能低成本复合电磁波介质陶瓷及其基础材料的 规模化生产技术及装备，人工片式电磁波介质的设 计、制备与规模化生产技术。

2. 无源集成模块及关键材料与技术

无源集成技术得以进入实用化和产业化阶段， 很大程度上取决于 LTCC 技术的突破。目前, 虽然 开发出了一些各具优势的无源集成技术，但是主流 技术仍以 LTCC 为主。一方面，优化材料 LTCC 性 能及制备方法，提高在国际高端应用中的占比；另 一方面, 兼顾其他几类无源集成技术, 研究开发相 应的关键材料、关键技术和重要模块。

(1) 系列化 LTCC 用电磁介质材料的研究。重 点研究具有系列化介电常数和磁导率、满足 LTCC 性能和工艺要求的陶瓷材料粉体和生产带, 形成我 


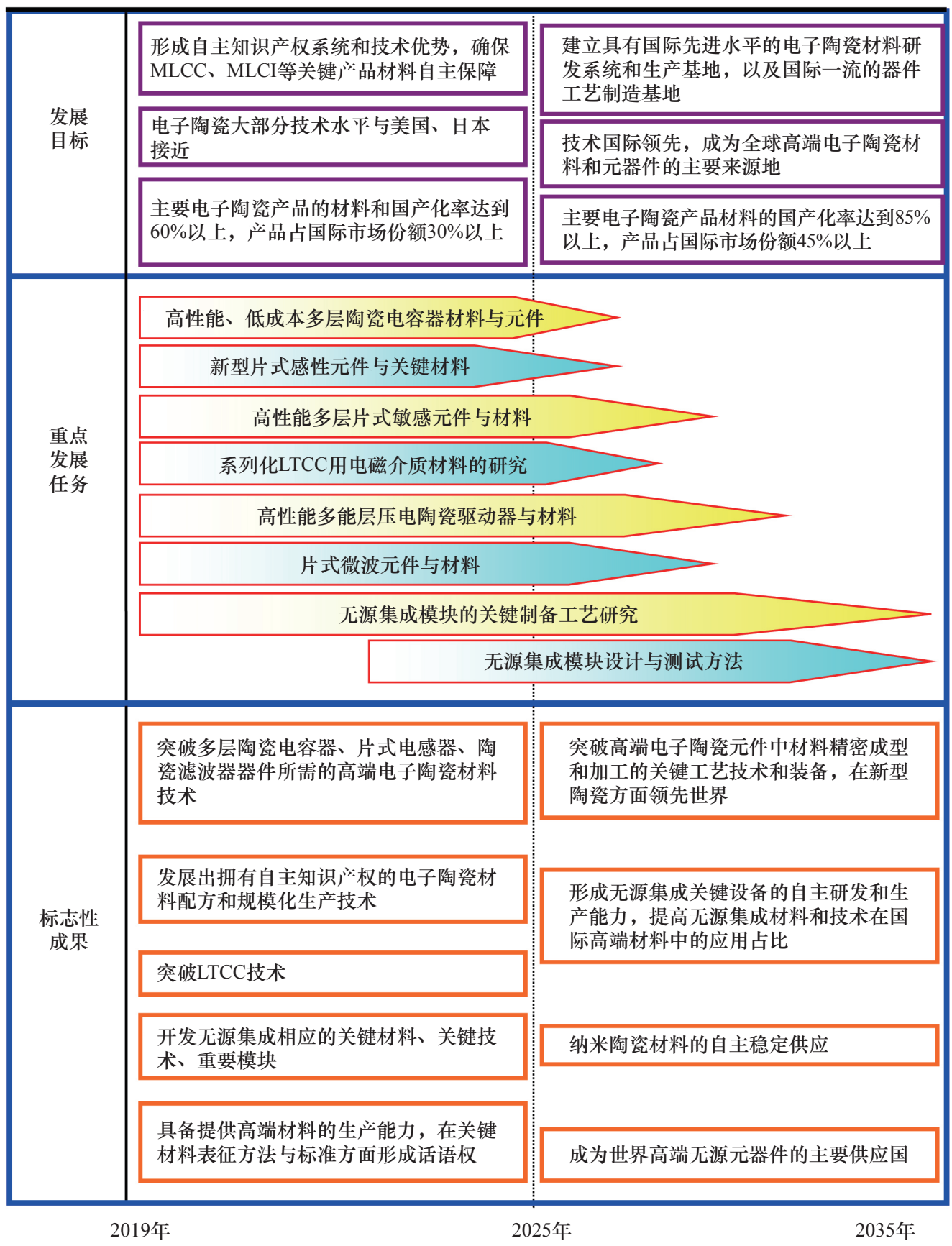

图 2 电子陶瓷发展路线图

国在 LTCC 材料领域的自主知识产权。

（2）无源集成模块的关键制备工艺研究。重点 研究无源集成模块制备的若干关键性工艺过程, 如 厚膜与薄膜制备工艺、微孔成孔与注浆工艺、精密 导体浆料印刷工艺、陶瓷共烧工艺等。

(3) 无源集成模块设计与测试方法。研究内容 包括无源集成模块设计软件的开发, 新型无源集 成结构特性的模拟与仿真, 高集成度无源集成模 块的设计, 以及无源集成模块的测试技术等。

\section{七、政策建议}

我国电子陶瓷材料和元件领域已形成了很好的 产业技术基础, 但是电子陶瓷作为一类重要战略新 材料, 其在高端电子陶瓷领域的强壮发展仍受到一 些关键材料技术、工艺技术及设备技术的制约。为 实现我国高端电子陶瓷产业的引领发展, 亟待强化 顶层统筹规划。

（1）将无源元件及关键电子陶瓷材料及无源电 
子元件纳入国家半导体产业发展战略布局中统筹考 虑，在国家支持微电子产业的重大研发计划中设立 无源元件专项，将国家支持芯片产业发展的各种优 惠政策扩展到电子陶瓷及无源电子元件行业。

（2）增加研究人员和资金投入，总体上强化研 发力量, 加强各研究单位直接的联系和交流协作, 开创一个以新材料研究为基础, 又有较强器件应用 研究背景与研究能力的综合研究开发体; 建立能将 成果及时、有效转化和具体实现 “产学研” 相结合 的有效机制。

(3) 统筹规划电子陶瓷材料与元器件产业链上 下游企业，强化原材料供应链以保证高纯、高稳定 性电子陶瓷前驱体的供应, 大力开展高端工艺装备 的研发, 加强无源元件和整机产业设计的自主创新, 加强相关标准的建设。

\section{参考文献}

[1] Moulson A J, Herbert J M. Electroceramics: materials, properties, applications [M]. England: Wiley, 2003.

[2] 南策文, 李龙土, 姚喜, 等. 信息功能陶瓷研究的新进展与挑战 [J]. 中国材料进展, 2010 (8): 30-36.
Nan C W, Li L T, Yao X, et al. New progress and challenges of information functional ceramics research $[\mathrm{J}]$. Materials China, 2010 (8): 30-36.

[3] 周济. 我国电子元件及材料研究发展的挑战与机遇 [J]. 电子元 件与材料, 2007, 26(1): 1-3.

Zhou J. Challenge and opportunity for the R\&D of electronic components and their key materials in China [J]. Electronic Components and Materials, 2007, 26(1): 1-3.

[4] 中国电子元件行业协会. 中国电子元件行业“十三五”发展规划 [R]. 北京: 中国电子元件行业协会, 2017 .

China Electronic Components Association.13th Five-Year development plan for electronic components [R]. Beijing: China Electronic Components Association, 2017.

[5] 王本立, 王兴艳. 全球电子陶瓷产业发展概况 [J]. 新材料产 业, 2016 (1): 9-12.

Wang B L, Wang X Y. Overview of the development of the global electronic ceramic industry $[\mathrm{J}]$. Advanced Materials Industry, 2016 (1): 9-12.

[6] Electronic Components Distribution. MLCC market update [EB/ OL]. (2018-07-12) [2020-05-18]. https://www.tti.com/content/ dam/MarketEYE/assets/MLCC\%20TTI\%20Supply\%20Chain\%20 Presentation.pdf.

[7] 代建清. 材料科学前沿之功能陶瓷 [EB/OL]. (2018-03-09) [2020-05-18]. https://www.docin.com/p-2089576908.html.

Dai J Q. Functional ceramics of frontiers of materials science [EB/OL]. (2018-03-09)[2020-05-18]. https://www.docin.com/ p-2089576908.html. 